\title{
A CONCEPTUAL FRAMEWORK IMPLEMENTING AN AS9100 QUALITY MANAGEMENT SYSTEM FOR THE AEROSPACE INDUSTRY
}

\author{
J.J. Oschman ${ }^{1 *}$
}

\section{ARTICLE INFO}

\begin{tabular}{|c|c|}
\hline $\begin{array}{l}\text { Article details } \\
\text { Submitted by authors } \\
\text { Accepted for publication } \\
\text { Available online }\end{array}$ & $\begin{array}{r}16 \text { Feb } 2018 \\
8 \text { Jul } 2019 \\
30 \text { Aug } 2019\end{array}$ \\
\hline $\begin{array}{l}\text { Contact details } \\
\text { * Corresponding author } \\
\text { oschmjj@unisa.ac.za }\end{array}$ & \\
\hline $\begin{array}{l}\text { Author affiliations } \\
1 \quad \text { Department of Opera } \\
\text { Management, Univers } \\
\text { Africa, South Africa }\end{array}$ & $\begin{array}{l}\text { ations } \\
\text { sity of South }\end{array}$ \\
\hline
\end{tabular}

DOI

http://dx.doi.org/10.7166/30-2-1930

\section{ABSTRACT}

This article proposes, through an extensive review of prominent International Organization for Standardization (ISO) literature, a conceptual framework implementing an AS9100 quality management system (QMS) for the aerospace industry. The conceptual framework developed in this study provides systematic collective knowledge for aerospace industries to understand the most important dimensions, and their mutual relationships, to deliver products and services ensuring customer satisfaction. The article presents a three-phase implementation methodology for achieving sustained success, offering useful practical relevance for any aerospace industry. The approach followed in this study can be used as a foundation for future studies in AS9100 QMS implementation.

\section{OPSOMMING}

$\mathrm{Na}$ aanleiding van ' $\mathrm{n}$ omvattende literatuurstudie van die mees prominente internasionale standardiseringsorganisasie (ISO) dokumente, stel hierdie artikel 'n konsepraamwerk voor vir die implementering van 'n AS9100 kwaliteitsbeheerstelsel (KBS) in die ruimte-industrie. Hierdie konsepraamwerk verduidelik op 'n sistematiese wyse die belangrikste dimensies en hul onderlinge verhoudings wat in die ruimte-indstrie onontbeerlik is vir die lewering van produkte en dienste wat kliënte tevrede stel. 'n Driefase implementeringsmetodologie word voorgestel met praktiese waarde vir voortgesette sukses in die ruimte-industrie. Die benadering wat in hierdie studie gevolg is, sou ook van toepassing wees in ander toekomstige studies van AS9100 gehaltebeheerstelsels.

\section{INTRODUCTION}

In the last decade there has been a growing need for the implementation of AS9100 (Aerospace Standard - requirements for aviation, space, and defence) quality management systems (QMSs) to build aerospace capabilities through transformation, by espousing continual renewal as a central theme in growth. The aerospace industry is a technologically-driven industry that is characterised by automation and digitisation and that integrates complex manufacturing systems and processes to accommodate the continuous increase in global air transport. By shaping the future of aviation, the AS9100 was developed by the International Aerospace Quality Group (IAQG) for the aerospace industry in the awareness that the industry must conform and contribute to recognised standards that meet and exceed customer satisfaction, including subcontractors and suppliers ([1]; [2]; [3]). The AS9100 part of the family of ISO standards defines quality standards based on the premise of minimum international requirements, which include all aviation, defence, and space organisations [4]. The implementation of the AS9100 is based on, and covers, 70 per cent of the ISO9000:2015. It complements aviation, space, and defence organisations with additional requirements for a QMS, providing documentation prerequisites based on the process approach necessary for trade product or services conformance. Garengo and Biazzo [5] and Oakland [6] suggest that the AS9100 standard should be used to establish a QMS that indicates confidence in aerospace's ability to use its own 
internal procedures and instructions to provide the design and development of products that fulfil customer needs and expectations. Adopting the AS9100 with successful implementation will ensure a high quality service offering that is safe and reliable during service use to achieve aerospace goals, to stay competitive, and to move ahead of competitors.

Overwhelming evidence confirms that aerospace industries all over the world are unambiguous in their strategic assessment of the future need for high standard products and services supported by the correct processes, ensuring that all operational airworthiness capabilities meet and secure quality, reliable, and safe air transport ([7]; [8]; [9]). Evans [10] and Sivakumar [11] found that the current operational priorities placed on worldwide aerospace industries, including the military, emphasise reliable and efficient future-related support initiatives, such as reliability improvements and functional enhancements of technologically sophisticated air systems. To meet the demands of these growing air transport responsibilities, both domestically and internationally, Foster [2] and Goetsch and Davis [12] claim that, for the practice of a certified and effective QMS within each aerospace industry to be AS9100 compliant/certified, is to gain significant competitive advantage, particularly when aiming for long-term success. Not only will this have a major effect on the methodologies employed to support air operations; it will also encourage aerospace industries to maintain an agile, responsive quality support system to sustain these operations. To meet customer needs consistently by controlling the core and support processes, the implementation and maintaining of any QMS requires a new journey of transforming and operating aerospace to succeed in its business practices ([13]; [14]; [15]).

While few suppliers in any country are 100 per cent aviation-, space-, or defence-oriented, the need to build on ISO9000 to attain AS9100 has increased. According to Fatima [16] and Tomic [17], the foundation of any aerospace industry is to be certified as conforming to the AS9100 and its application in the form of a QMS-documented system for controlling formalised business processes and ensuring quality products and service. When AS9100 was released by the European Association of Aerospace Industries in October 1999, fully incorporating the current version of ISO9000 (a quality standard maintained by the International Organization for Standardization [60]), it added different scopes essential to every QMS that could be applied in many different aerospace industry cultures. On these grounds, aerospace manufacturers, suppliers, and maintenance repair organisations worldwide seek compliance with AS9100 as a condition of doing business ([18]; [19]).

However, far too little attention has been paid to a conceptual framework to implement an AS9100 QMS for the aerospace industry to clarify the critical role of a QMS in the aerospace industry operations, thus ensuring an increase in its current commitment to air assets and its sustainable product and service fitness mission ([2]; [3]). Aligning the support with the changing aerospace requirements is therefore one of the most critical design requirements for a conceptual AS9100 QMS framework if it is continually to improve aerospace industries' overall performance and efficiency ([20]; [21]). Garengo and Biazzo [5] and Leonard [22] highlight the fact that, for a conceptual framework to implement the AS9100 QMS, it needs to move strategically into the future of the aerospace industry, to support the increased growth of more than 2.1 million ISO9000-certified aerospace-related companies worldwide, and to reach and enhance world-class sustainable quality standards. They further point out that, to meet the rigorous demands of current and future commitments throughout the supply chain, the aerospace industry must design, align, and integrate its own internal QMSs with related management system requirements. This will enable the industry to achieve optimal levels of effective and efficient airworthiness requirements in the preparation, employment, and support of its material and human assets. Moreover, Sharma, Garg and Agarwal [23], and Stadnicka and Antosz [24] emphasise the fact that the purpose of the aerospace industry implementing an AS9100 QMS is to provide overall quality and internal controls, while providing a marketing advantage associated with this certification.

This article provides a conceptual framework within which effective support can be developed and sustained in any aerospace organisation. In essence, the framework seeks to establish a bridge between the current situation and the future state, where the aerospace industry should provide effective quality support to its primary air power mandate. To ensure that capability meets operational requirements, the aerospace industry must comply with the production of safe and reliable products and services, supported by sustained continuous improvement practices to provide stability, discipline, and consistency in the operations process. Despite this, very few studies have investigated the impact of an AS9100 QMS framework on aerospace industries, and not much has been written on the advantages of such a conceptual framework implementing a QMS in terms of 
the dynamics of performance outcomes that are important to the aerospace industry. This paper seeks to examine the significance of the proposed conceptual AS9100 QMS framework that was developed, based on an extensive conceptual literature review, and aims to contribute to this growing area of research by exploration.

\section{METHODOLOGY}

A qualitative method was used in this investigation, based on an extensive holistic literature review, integrating material to establish critical dimensions for the need for an AS9100 QMS framework. Generic QMS dimensions have been investigated, and research extensively shows that a framework needs a lot of attention to transform any aerospace industry so that it competes successfully and ensures its long-term economic health ([8], [34]; [33]; [35]; [22]). To fill the gap in the literature, the study on which this article is based explored the use of important dimensions to support the implementation of an AS9100 QMS framework. Therefore, in this study, the research question was as follows: Is there a direct correlation between an AS9100 QMS framework and its successful implementation? This is followed by the identification of critical primary and supportive dimensions that were incorporated into a proposed conceptual framework for the successful implementation of an AS9100 QMS in the aerospace industry. These dimensions are explained in detail, followed by guidelines for organising the implementation of the conceptual framework through a three-phase approach, based on the integrated relationships among the dimensions, to improve global competitiveness. The study showed that the effect of implementing an AS9100 QMS framework is significant in aerospace organisations. Although the data is not presented, the conceptual framework was tested from 2013 to 2015 in the South African Air Force (SAAF). The last section of the article contains the conclusion drawn from the research.

\section{THE NEED FOR AN AS9100 QMS FRAMEWORK}

Various authors, including Campbell [13] and Miguel and Dias [25], have pointed out that an integrated QMS is the foundation for the management of any aerospace organisation. These authors argue further that the philosophy of a QMS must be understood before any aerospace industry can benefit from the establishment and requirements of AS9100. Oschman [26] found that, to understand a QMS, a clear definition of quality is vitally important. According to Oschman, "Quality is the degree of added value to products and/or service delivery as perceived by all the stakeholders through conformance to specifications, and the degree of added excellence to products and/or service delivery through a motivated workforce, in order to meet customer satisfaction" [26]. To comply with this definition, a QMS needs a set of organisational activities, such as policies, procedures, plans, structures, resources, processes, and a delineation of responsibility with authority, aimed at directing and controlling an organisation. These activities are deliberately aimed at achieving product or service quality levels that are consistent with customer satisfaction, as well as achieving the organisation's objectives to continually improve the effectiveness and efficiency of its performance ([8]; [12]; [21]). Combining these components, Fakhri [27] and Leonard [22] claim that the main purpose of a QMS is to define how an organisation works and how quality is managed by focusing on customer requirements, and then strengthening the supply chain through clear control of core operational processes.

Any QMS document must reflect the integration of seven major areas: context of the organisation, leadership, planning, support, operations, performance evaluations, and improvement. These major areas are supported by seven ISO principles: customer focus, leadership, engaging with people, process approach, improvement, evidence-based decision-making, and relationship management all to be used by top management as they lead their organisations and improve sustained success ([10]; [28]; [29]). For Collins and Stieger [30] and Munroe [31], these seven areas, with their principles, form the model of a process-based QMS. To make the documentation of the standard operating procedures and record-keeping efficient for adding value to the products or services for internal and external customers, the QMS must establish sequences and linkages for all the core and supporting processes with its primary and secondary procedures and activities.

As well as the widespread literature on the elements and importance of a QMS document processbased model, it was found, in exploring the use and advantages of a QMS, that many authors, including Anderson and Anderson [32], Fakhri [27], and Harun and Cheng [33], have identified and cited critical success factors (CSFs) of QMS implementation based on ISO Standards. However, there 
is relatively little research on formal AS9100 QMS implementation frameworks. It is thus prudent to create a deeper insight into the various dimensions of an AS9100 QMS framework. All aerospace organisations need the development and implementation of a formal AS9100 QMS to (1) improve customer satisfaction by fulfilling customer requirements; (2) achieve continual improvement of organisational performance and competitiveness; (3) use organisational resources cost-effectively to continually improve the processes required for developing effective products and services; and (4) comply with regulatory airworthiness requirements in order to achieve high levels of performance, thereby ensuring that safe, quality products, equipment, and systems are consistently provided to the customer on time to gain customer confidence ([34]; [33]; [35]). Boase [8] and Leonard [22] suggest that, to be registered, any aerospace organisation must demonstrate conformity by using a QMS that incorporates all QMS principles and process-based areas to continuously sustain and maintain the QMS, assuring customers worldwide that the products and services will meet their needs and requirements.

The next section is guided by the AS9100 QMS implementation framework provided in Figure 1, which has been widely developed, used, and adapted for four years in the SAAF.

\section{DIMENSIONS OF AN AS9100 QMS FRAMEWORK}

This section presents a review of the dimensions indicated by the literature as necessary for implementing an AS9100 QMS, using a conceptual framework. According to Oakland [6], 'dimensions' are the key activities needed by an organisation to perform well and to achieve its mission. A large and rapidly growing body of literature on QMSs argues in favour of integrated dimensions ([36]; [37]; [23]). Due to their dependability on each other in supporting the implementation of any QMS, the role and functions of the dimensions in the QMS need to be integrated and understood through the systems-thinking approach. Thus they form a flexible and workable AS9100 QMS framework, ensuring that all aerospace organisations are standardised and organised. This will enable compliance with customer requirements about the type of activity and product or service being offered, and will improve processes, making these aerospace organisations more competitive ([31]; [6]). The framework can be used as a prerequisite when applying an AS9100 QMS to any aerospace organisation.

An intensive literature review indicated that researchers use 13 dimensions, divided into seven primary and six supportive dimensions (see Table 1), in most QMS implementation processes. These processes also require the combination of quality principles and ISO standard clauses to represent a framework for AS9100 QMS (Figure 1). Moreover, the 13 dimensions must operate simultaneously to establish an AS9100 QMS within an aerospace organisation. Table 1 explains the primary and supportive dimensions for an AS9100 QMS by summarising the literature on the critical role, purpose, and unique characteristics of the 13 dimensions in aerospace organisations (which may vary from manufacturing to service aerospace organisations), and the various aspects they bring into the picture.

Table 1: Explanation of primary and supportive dimensions' terms

\begin{tabular}{|c|c|}
\hline $\begin{array}{l}\text { Primary } \\
\text { dimensions }\end{array}$ & Explanation of primary dimensions as found in the literature \\
\hline $\begin{array}{l}\text { Leadership } \\
\text { commitment }\end{array}$ & $\begin{array}{l}\text { Leadership commitment, as a primary driver dimension, should establish unity of purpose and } \\
\text { direction by creating an organisation-wide quality environment within the aerospace } \\
\text { organisation. This will enhance customer satisfaction and increase market share (Abdallah } \\
\text { [38]; Al-Rawahi \& Bashir [7]; Dervitsiotis [39]; Foster [2]; Karapetrovic, Fa \& Saizarbitoria } \\
\text { [14]; Oakland [6]; Russell [29]; Sivakumar [11]; Yahya \& Goh [36]). }\end{array}$ \\
\hline $\begin{array}{l}\text { Strategic } \\
\text { planning }\end{array}$ & $\begin{array}{l}\text { Strategic planning should provide clear guidance by describing the aspirations through a } \\
\text { philosophy, vision, policy, core beliefs, values, and objectives with goals and processes. In } \\
\text { this way, it makes visible its strategic intentions for the future, including exploration, } \\
\text { implementation, and a sustainability plan by meeting customer, statutory, and regulatory } \\
\text { requirements (Fotopoulos \& Psomas [40]; Gates [41]; Imbeah [42]; Laux \& Hurburgh [9]; } \\
\text { Lewis, Pun \& Lalla [43]; Oschman [26]; Munroe [31]; Soko [44]; Tomic [17]). }\end{array}$ \\
\hline $\begin{array}{l}\text { Gap analysis } \\
\text { system }\end{array}$ & $\begin{array}{l}\text { Aerospace organisations should compare existing internal management processes with } \\
\text { procedures or any previous quality efforts to determine what the present operation process } \\
\text { is, what already exists, and whether they meet AS9100 requirements; and if not, how it should } \\
\text { be modified, developed, or created to fill documentation gaps to meet AS9100 requirements, } \\
\text { linked with ISO principles and clauses (Barker [1]; Boase [8]; Boyd \& Stolzer [45]; Leonard } \\
\text { [22]; Rosenberg [37]; Sharma, Garg \& Agarwal [23]; Thomas [15]). }\end{array}$ \\
\hline
\end{tabular}




\begin{tabular}{|c|c|}
\hline $\begin{array}{l}\text { Primary } \\
\text { dimensions }\end{array}$ & Explanation of primary dimensions as found in the literature \\
\hline QMS & $\begin{array}{l}\text { The QMS should be the main process-oriented documentation system for any aerospace } \\
\text { organisation, comprising a quality manual, procedures (business processes), work } \\
\text { instructions, and forms with records. These must be compatible with all organisations' } \\
\text { strategic directions, which should interact and integrate with each other to continuously and } \\
\text { consistently improve performance. This will ensure that requirements for all products and/or } \\
\text { services delivered meet customer specifications by controlling the core processes that affect } \\
\text { them, such as sales orders, design, production, inspection, and delivery. Yet the } \\
\text { requirements go beyond these 'core' processes, and must also address support processes such } \\
\text { as purchasing, training, calibration, maintenance, and performance metrics (Boyd \& Stolzer } \\
\text { [45]; Evans [10]; Fakhri [27]; Garengo \& Biazzo [5]; Gordon [28]; Oschman [26]; Pycraft, Singh } \\
\text { \& Phihlelea [21]; Schlickman [47]; Stolzer \& Halford [46]). }\end{array}$ \\
\hline $\begin{array}{l}\text { Internal } \\
\text { audit system }\end{array}$ & $\begin{array}{l}\text { After the implementation of the AS9100 QMS documentation system, aerospace organisations } \\
\text { should have systematic and regular internal audits to evaluate effectiveness and the status } \\
\text { of the internal QMS, ensuring it complies with AS9100 requirements as well as the } \\
\text { organisations' documented work practices and processes (Leonard [22]; Myhrberg, Valdemar } \\
\text { \& Crabtree [19]; Sivakumar [11]; Smithers Quality Assessments [48]; To, Lee \& Yu [49]; Harun } \\
\text { \& Cheng [33]). }\end{array}$ \\
\hline $\begin{array}{l}\text { Continuous } \\
\text { improvement }\end{array}$ & $\begin{array}{l}\text { Continuous improvement should be an objective for aerospace organisations through the } \\
\text { application of all eight ISO principles. This will create incremental and innovative ongoing } \\
\text { improvements for its employees, and to its processes, procedures, products, and services, } \\
\text { and will thus continually improve its overall airworthiness performance goals (Boase [8]; Chen } \\
\text { \& Cheng [34]; Fatima [16]; Fotopoulos, Psomas \& Vouzas [50]; Goetsch \& Davis [12]; Lee \& } \\
\text { Kim [18]; Russell [29]; Stadnicka \& Antosz [24]). }\end{array}$ \\
\hline $\begin{array}{l}\text { Customer } \\
\text { and } \\
\text { stakeholder } \\
\text { satisfaction }\end{array}$ & $\begin{array}{l}\text { Customer and stakeholder satisfaction should be deeply understood, as it is the final arbiter } \\
\text { of product and service quality to be achieved by delivering excellent value with the main } \\
\text { objective of satisfying customers' and stakeholders' needs and expectations (Abdullah et al. } \\
\text { [51]; Dervitsiotis [39]; Fotopoulos, Psomas \& Vouzas [50]; Garengo \& Biazzo [5]; Goetsch \& } \\
\text { Davis [12]; Haupt [52]; Karapetrovic, Fa \& Saizarbitoria [14]; Miguel \& Dias [25]; Oakland [6]; } \\
\text { Steudel [3]). }\end{array}$ \\
\hline
\end{tabular}

\begin{tabular}{|c|c|}
\hline $\begin{array}{l}\text { Supportive } \\
\text { dimensions }\end{array}$ & Explanation of supportive dimensions as found in the literature \\
\hline $\begin{array}{l}\text { Engagement } \\
\text { of people }\end{array}$ & $\begin{array}{l}\text { Employees are the centre of any QMS implementation process. It is essential to involve them } \\
\text { in developing their work procedures and processes, and to equip them with the necessary } \\
\text { skills and knowledge to provide innovation and creativity at all levels of the workforce to } \\
\text { ensure high quality products and services and, in the long run, to maximise technology use } \\
\text { (Abdallah [38]; Dervitsiotis [39]; Fotopoulos, Psomas \& Vouzas [50]; Laux \& Hurburgh [9]; } \\
\text { Oakland [6]; Rosenberg [37]; Stolzer \& Halford [46]; Tomic [17]). }\end{array}$ \\
\hline $\begin{array}{l}\text { Relationship } \\
\text { management }\end{array}$ & $\begin{array}{l}\text { Strong alliances and teamwork will enhance the important co-dependent relationships } \\
\text { between customers, suppliers, partners, and stakeholders. Strategic relationships based on } \\
\text { trust will not only improve the quality of processes, products, and services, but will also } \\
\text { optimise the growth and effective use of resources (Fakhri [27]; Fatima [16]; Johansson \& } \\
\text { Stenmark [59]; Kreamer-Mbula [35]; Lee \& Kim [18]; Gordon [28]; Lewis, Pun \& Lalla [43]; } \\
\text { Miguel \& Dias [25]; Russell [29]; Sivakumar [11]). }\end{array}$ \\
\hline $\begin{array}{l}\text { Service } \\
\text { culture } \\
\text { forming }\end{array}$ & $\begin{array}{l}\text { The forming of a service culture creates service delivery that results in an elevated status in } \\
\text { society and a desire to adhere to aerospace standards or to pursue the objectives of support } \\
\text { excellence (Abdallah [38]; Farooqui \& Ahmed [57]; Gates [41]; Laux \& Hurburgh [9]; Leonard } \\
\text { [22]; Stolzer \& Halford [46]; Thomas [15]; Yahya \& Goh [36]). }\end{array}$ \\
\hline $\begin{array}{l}\text { Evidence } \\
\text { based } \\
\text { decision- } \\
\text { making }\end{array}$ & $\begin{array}{l}\text { The selection, collection, review, alignment, and integration of analysed data for strategic } \\
\text { progression to ensure improvement in decision-making for the future will strengthen success, } \\
\text { competitive performance, and progress (Barker [1]; Boyd \& Stolzer [45]; Coppinger [20]; } \\
\text { Garengo \& Biazzo [5]; Gates [41]; Karapetrovic, Fa \& Saizarbitoria [14]; Lee \& Kim [18]; Miguel } \\
\& \text { Dias [25]; Schlickman [47]; Stadnicka \& Antosz [24]; Tomic [17]). }\end{array}$ \\
\hline $\begin{array}{l}\text { Process } \\
\text { approach }\end{array}$ & $\begin{array}{l}\text { Fundamental to any QMS is the identification and development of customer-driven core and } \\
\text { sub-processes. This needs to be systematically managed through continuous re-engineering } \\
\text { and reviewing to ensure accuracy standards and structured formats for all products and } \\
\text { services. Innovative and creative ideas that deliver continual benefits for the organisation } \\
\text { and its customers should be used. Quality excellence derives from well-designed work } \\
\text { processes, which comprise a set of interrelated or interacting activities that transform inputs } \\
\text { into outputs that lead to cost-effectiveness (Boase [8]; Chen \& Cheng [34]; Collins \& Steiger } \\
\text { [30]; Farooqui \& Ahmed [57]; Fotopoulos, Psomas \& Vouzas [50]; Karapetrovic, Fa \& } \\
\text { Saizarbitoria [14]; Oschman [26]; Pycraft, Singh \& Phihlelea [21]; Stadnicka \& Antosz [24]). }\end{array}$ \\
\hline
\end{tabular}




\begin{tabular}{|l|l|}
\hline $\begin{array}{l}\text { Supportive } \\
\text { dimensions }\end{array}$ & Explanation of supportive dimensions as found in the literature \\
\hline $\begin{array}{l}\text { Systems } \\
\text { thinking }\end{array}$ & $\begin{array}{l}\text { To convert inputs into outputs as a common goal for product and service delivery benefits, it } \\
\text { is necessary to identify all processes in the organisation, and their interdependence. These } \\
\text { processes should then be managed as a complete system through the systematic integration } \\
\text { of appropriate information and data via various interrelated processes (Campbell [13]; Conti } \\
\text { [53]; Evans [10]; Goetsch \& Davis [12]; Harun \& Cheng [33]; Imbeah [42]; Myhrberg, Valdemar } \\
\text { \& Crabtree [19]; Oakland [6]; Steudel [3]). }\end{array}$ \\
\hline
\end{tabular}

\section{A CONCEPTUAL FRAMEWORK IMPLEMENTING AN AS9100 QUALITY MANAGEMENT SYSTEM}

A proposed framework, the AS9100 QMS (see Figure 1), is introduced and described in this section. It is supported by an explanation of the implementation process of the framework, which, in three phases, focuses on achieving benefits, using all 13 primary and supportive dimensions identified in Table 1. The interactive and overlapping relationships of the dimensions, and the fitting together of the framework, have been customised to fit the needs of any aerospace organisation when implemented. This will provide guidance on how the AS9100 QMS framework can be applied and deployed for achieving purposeful results to create processes, products, services, and systems that serve customers effectively. Figure 2 shows the interrelationship between the primary and supportive dimensions based on the systems-thinking approach. This will jointly enhance organisational excellence, affecting every aspect of the aerospace industry. The integrative approach of the framework was driven by the complexity of work that must be done in aerospace industries. The framework needs a three-phase implementation process, illustrated in Table 2, where the dimensions interact with each other, acting as building blocks for implementation. This requires a continuous commitment to improve competitive performance. In the three phases, the six supportive dimensions (see Table 1 and Figure 2 ) must be integrated and continuously considered in all seven primary dimensions, as indicated in Figure 2.

Table 2: AS9100 implementation phases

\begin{tabular}{|l|l|}
\hline Phase & Purpose \\
\hline Start-up phase & $\begin{array}{l}\text { The AS9100 QMS framework is adopted and explored through the two start-up } \\
\text { dimensions - leadership commitment and strategic planning. }\end{array}$ \\
\hline Integration phase & $\begin{array}{l}\text { This is the initial implementation of the AS9100 QMS through a gap analysis and the } \\
\text { documentation of the QMS. Internal audits are done thereafter, based on the } \\
\text { application of the QMS. }\end{array}$ \\
\hline Result phase & $\begin{array}{l}\text { After full implementation, the first two phases are continuously sustained and } \\
\text { maintained to ensure customer and stakeholder results. }\end{array}$ \\
\hline
\end{tabular}

\subsection{Phase 1: Start-up (see Figures 1 and 2)}

In phase 1 , the two dimensions of leadership commitment and strategic planning are the most important superordinate drivers in implementing the AS9100 QMS framework, integrated with the six supportive dimensions (see Figures 1 and 2). These two superordinate dimensions need a lot of attention to steer any aerospace organisation towards competitive success, ensuring long-term economic health ([30]; [52]). According to Foster [2], a superordinate driver creates higher-end benefits, bigger than the individual organisation. These two start-up dimensions must act mutually as exploration and adoption by leadership to ensure readiness for implementation. 


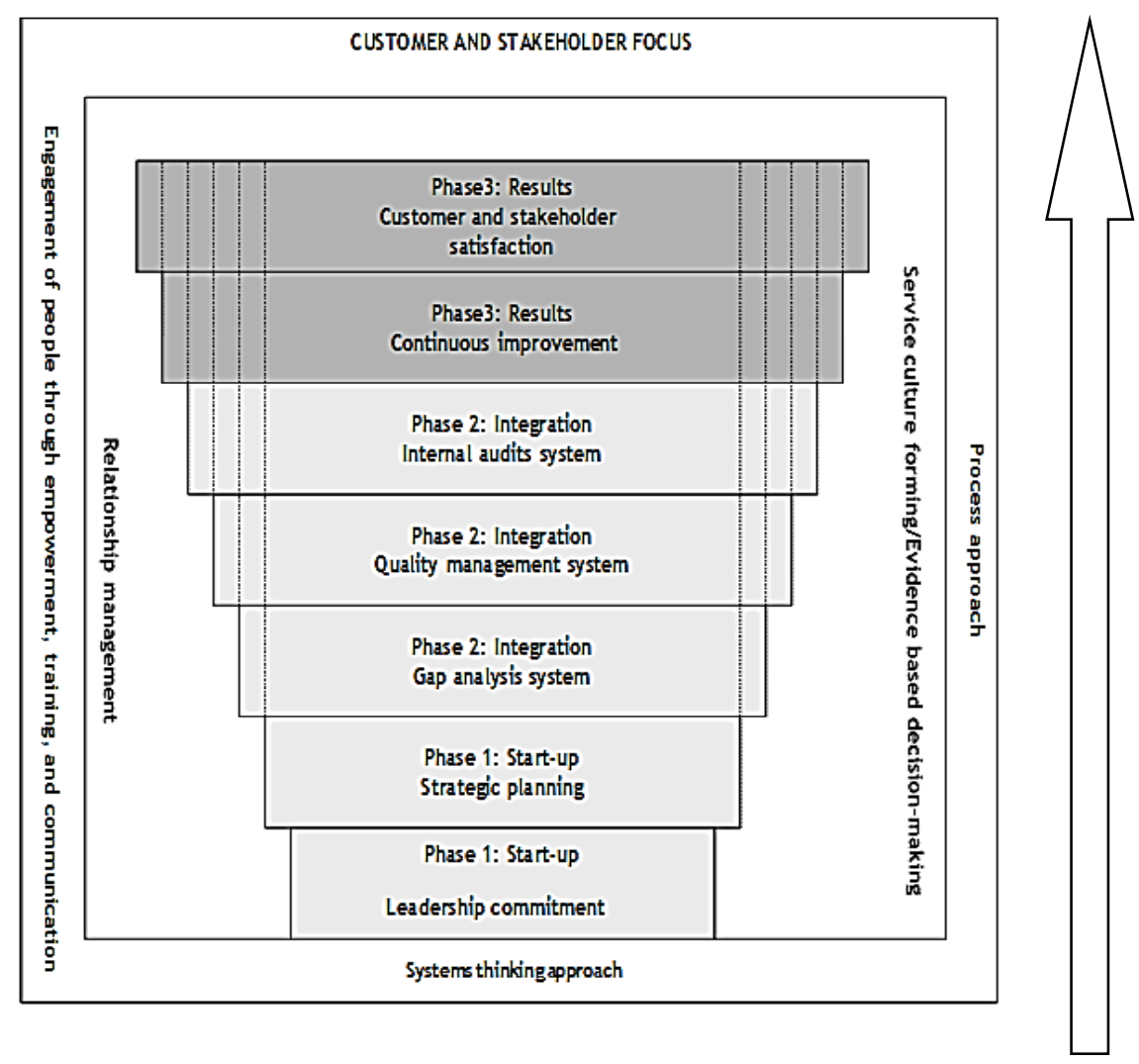

Figure 1: Proposed AS9100 framework adopted from Oschman [26]

\subsubsection{Leadership commitment}

To gain optimum productive and high-level performance over the long term, leadership must commit to adhere to the highest quality standards ([34]). Quality improvement efforts depend on unity of purpose and direction to reach the desired outputs, and must be infused by leadership. In grounded theory research, Abdullah et al. [51], Dervitsiotis [39], and Foster [2] found that leaders increase the involvement of their workforce through active engagement and relationship-forming by communicating the importance of meeting customer, statutory, and regulatory requirements. These authors explain that commitment is psychological energy, which is more than morale and job satisfaction: it is a personal desire to contribute to the success of the organisation, and to accept responsibility in a spontaneous, self-generated, and self-directing way, which, in turn, powers the organisation's system. It provides for the funding, resources, and slack time so that all of the quality improvement efforts are successful. 


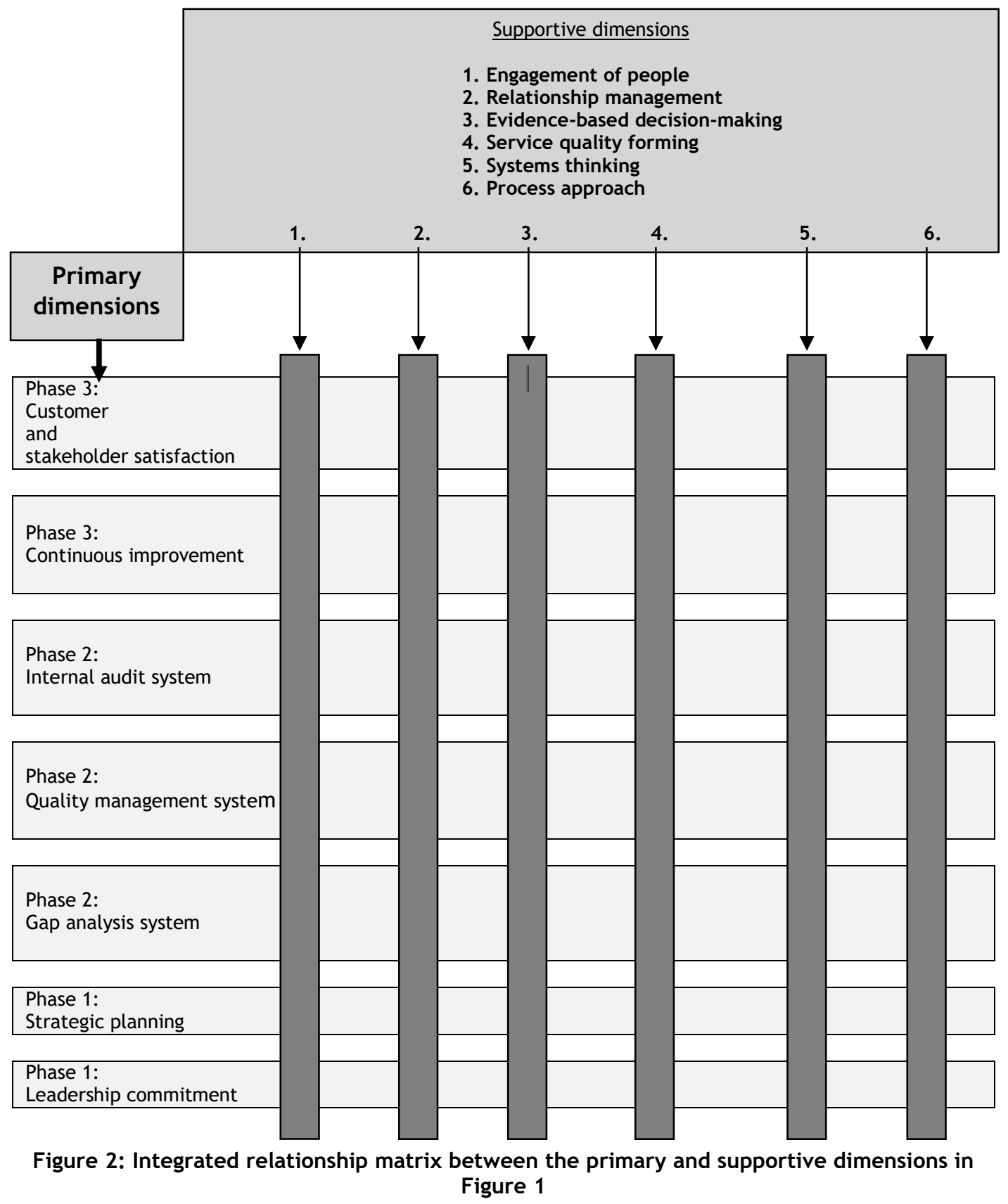

According to Evans [10] and Foster [2], an AS9100 QMS is a customer-driven management strategy, starting with leadership commitment, but involving participation at all levels of work within the organisation. Promotions at all levels of the organisation have a quality focus, harnessing all the resources of the organisation to achieve cost-effective world class standards. All cost aspects of product and service rendering will thus improve the competitiveness, effectiveness, and flexibility of the organisation as a whole. Abdallah [38] and Fakhri [27] agree in emphasising that this leadership commitment must ensure affordability so that the execution of the assigned AS9100 QMS implementation can be funded and supported by the operating budget to ensure improved performance.

Unless the leadership layer of any aerospace organisation is kept abreast of emerging best practices in the creation and sustaining of the AS9100 standard, it is unlikely to be ready to provide the quality of leadership and guidance required to steer the complex aerospace environment to success. 


\subsubsection{Strategic planning}

Oakland [6] and Evans [10] indicate that there is scant literature on the crucial role of leaders embracing a quality culture by formalising a strategic plan to implement AS9100 QMS. In grounded theory research, Conti [53] found that strategic planning requires constant infusion as one of the most important critical success factors and foundations when implementing AS9100 QMS. This will ensure sustainable product and service fitness for purpose. The critical dependency between strategic planning and leadership commitment in any AS9100 QMS will provide direction and control for tactical plans and daily operations to capitalise on opportunities in the marketplace. The underlying argument in favour of this dependency is to anticipate the product and service expectations of both current and future customers, ensuring the core source of vitality and vigour in the workplace in order to achieve excellence ([37]). Karapetrovic, Fa and Saizarbitoria [14] emphasise the fact that this consensus view will not only determine the direction of the organisation and its future outlook, but also indicate how to achieve that future, which is based on the process of factual decision-making.

Smithers Quality Assessments [48] and To, Lee and Yu [49] highlight the fact that any intended strategic plan to implement an AS9100 QMS should provide critical interrelated links - namely, that the strategic plan (1) must have long-term goals for customer/stakeholder satisfaction through employees; (2) must provide the means to achieve these goals within the context of AS9100 QMS; (3) must establish a new, continuous improvement culture, ensuring long-term performance success by increasing value to customers; and (4) must ensure that resources are available. According to Conti [53], Gates [41], and Munroe [31], the collective strength of such a strategic plan is ultimately to build potential and sustainable capabilities, so that its depth gives flexibility to the organisation by increasing its range of responses to emerging opportunities and threats. On these grounds, Oschman [26] and Myhrberg, Valdemar and Crabtree [19] indicate that an AS9100 must have structured, ongoing employee awareness training. Equally important is the incorporation of employee suggestions through review meetings at every level of an organisation's functions. It is crucial for different categories of employees to exercise commitment, cooperation, and collective creativity for AS9100 QMS implementation. Chen and Cheng [34] assert that the main premise behind engaging employees is to enable and encourage a workforce that seeks excellence in everything they do. This creates long-term success, which is essential to profitable business development in the long run.

Effectively preparing the organisation in the start-up phase, which is the foundation for implementing an AS9100 QMS, is necessary so that phase two can integrate the AS9100 QMS document of the organisation by cascading its implementation through three dimensions - gap analysis, QMS, and internal audit - that are integrated with the first two dimensions (leadership commitment and strategic planning) together with the six supportive dimensions (see Figure 1).

The supportive dimensions should be continuously considered in all six primary dimensions, as indicated in Figure 2.

\subsection{Phase 2: Integration (see Figures 1 and 2)}

Phase two comprises (1) the gap analysis, (2) the development of a documented QMS based on the AS9100 Standard, and (3) the internal audit system. These are the initial implementation actions that must take place to bring the AS9100 QMS into full operation.

\subsubsection{Gap analysis}

Foster [2] explains that 'gap analysis' refers to desired conformance versus actual conformance performance levels in manufacturing, as well as expected versus actual levels of service. In a QMS, performing a gap analysis clearly identifies which elements in the QMS are not being fully met. Once the aerospace organisation has accepted the AS9100 QMS as a strategic necessity for focusing on products and service delivery, the first step is to begin with a gap assessment. The aim of this assessment is to identify gaps that need corrective action through a documented process improvement system, which is required for a system that is AS9100-compliant ([54]; [16]). Identifying and correcting these gaps should transform nonconformities into reliable and consistent performance and dependability to honour promises to customers. According to Pycraft, Singh and Phihlelea [21] and Russell [29], the SERVQUAL model can be used to determine gaps between managerial and customer perceptions. They point out that the SERVQUAL includes ten determinants of service quality dimensions, and uses a questionnaire to test the relationships in order to measure customer perceptions. After a gap analysis, a clear picture is gained of how an existing management 
system compares with the intended AS9100 QMS. Foster [2] suggests that a detailed process development plan should be developed to fill these gaps through corrective actions by using a standardised AS9100 gap analysis template, helping the aerospace organisation to comply fully with the AS9100. He points out that this template, called the 'process development form', should be used to list the remedial actions that should be formulated to fill the gaps. These listed remedial actions can be formulated by turning gap analysis questions into simple action statements. Key responsibilities to close all gaps should include approval from top management; workforce training to produce service quality; process design using re-engineering techniques; aligned support structures, systems, and resources; and careful communication with all stakeholders to correct nonconformities within estimated completion dates ([13]; [43]; [48]). Again, the six supportive dimensions - engaging employees through training, communication, and empowerment, relationship management through teamwork, service culture forming, evidence-based decision-making, a process approach, and systems thinking - play a prominent role in resolving the gap analysis.

After the gap analysis, leadership approval is necessary to move to the most vital component in phase two, the development of the documented QMS. The leadership, who in phase 1 incorporated the AS9100 QMS vision into the strategic plan, must now approve the gap analysis with the rectification plans. These plans must be in place so that the inputs can be used to develop the QMS.

\subsubsection{Quality management system}

After the gap analysis, aerospace organisations have a clearer picture of how their existing management systems compare with the AS9100 standard. Evans [10] suggests that, from the gap analysis, the development of the QMS document to conform to the AS9100 standard must start with the formal endorsement and commitment of top management, ensuring the correct level of supporting resources. These resources would include the appointment of a quality manager to develop the QMS using the seven major areas for implementation; this should be interconnected with the seven principles discussed in paragraph 3: (1) context of the organisation; (2) leadership; (3) planning; (4) support; (5) operations; (6) performance evaluations; and (7) improvement. The foundation of the AS9100 QMS is 20 process-based elements that can be incorporated into the seven major areas. The process-based elements are: (1) management responsibility; (2) quality system; (3) contract review; (4) design control; (5) document control; (6) purchasing; (7) purchaser-supplied product; (8) product identification and tractability; (9) process control; (10) inspection and testing; (11) inspection, measuring, and test equipment; (12) inspection and test status; (13) control of nonconforming products; (14) corrective action; (15) handling, storage, packaging, and delivery; (16) quality records; (17) internal quality audits; (18) training; (19) servicing; and (20) statistical techniques ([55]; [16]; [17]). Boase [8] emphasises the fact that developing and writing procedures for each of these 20 elements is a critical component of a QMS, and it is imperative that the procedures are developed in close consultation with the staff who perform the process as part of their duties.

The appointed quality manager must have special leadership traits, ensuring that the QMS as a quality manual is developed from a detailed plan, linking all 20 elements above with target dates, to create a document that describes organisational structures, procedures supported with flowcharts in the form of activities, and functional responsibilities. The document must also include work instructions as standard operating procedures, supported by the forms and records that relate to the specific aerospace industry and that affect products and service delivery, thereby ensuring customer satisfaction ([7]; [11]). Evans [10], Leonard [22], and Oakland [6] indicate that, when structuring these 20 process-based elements to establish the QMS document, there should be ample support for the claim that Deming's iterative four-step plan-do-check-act (PDCA) cycle is used as the methodology to coordinate all 20 process-based elements for continuous improvement efforts. These authors claim that, when implementing and reviewing these 20 process-based elements, local management teams - with inputs from customers, suppliers, employees, and consultants with special skills - should be used to (1) plan processes that balance aggregate demand and supply to develop a course of action that best meets sourcing, production, and delivery requirements for the customer; (2) implement the processes to meet planned and actual demands, as well as processes that transform materials and products into a finished state; (3) check by monitoring and measuring all processes to see whether actual achievements meet planned objectives; and (4) act on improvement plans continuously to achieve better results that extend to post-delivery customer support. 
Larson and Kerr [56] conclude that drafting and implementing an AS9100 QMS needs specialised internal training. The focus should be on the specific aerospace culture when teaching staff to develop and re-engineer functional processes that support quality of work and service delivery. These authors suggest that a council for continuous improvement $(\mathrm{CCl})$ be established in each aerospace organisation and should develop a curriculum for improving work processes. Such a body could also pool knowledge and resources to develop quality-related training materials that meet the needs of all sections of the organisation. The study to establish a QMS has shown that successful quality training is significant, and that employees need to understand how to apply the AS9100 standard.

\subsubsection{Internal audit}

Before the QMS can be optimised and sustained, all the new documented QMS procedures, processes, and work instructions must be evaluated through scheduled planned internal audits to measure, monitor, and improve them ([55]). Generating and maintaining records is necessary to show how effectively the QMS is functioning. This will give the leaders enough information to determine whether the developed QMS meets the requirements of the AS9100 standard. Foster [2] and Miguel and Dias [25] emphasise the importance of internal audits, which should be used to compare current practice against structural measures in an aerospace organisation, with the intent of re-energising quality efforts. Leonard [22], Rosenberg [37], and Tomic [17] argue that internal audits should apply the six principles for auditing, stated in the AS9100 guidelines for auditing a QMS. These principles are: (1) the foundation of professionalism, namely integrity; (2) fair presentation by reporting truthfully and accurately; (3) professional care through the application of diligence and judgement in auditing; (4) confidentiality by ensuring the integrity and security of information; (5) independence, ensuring the impartiality of the audit and the objectivity of the audit's conclusions; and (6) an evidence-based approach to determine whether QMS is a rational method for reaching reliable and reproducible audit conclusions in a systematic audit process. The organisation should conduct internal audits to determine whether the QMS conforms to the planned requirements of this international standard. To, Lee and Yu [49] confirm the significant benefits of continuous internal audits that evaluate whether documented procedures and work instructions are effective, and whether corrective and preventative actions are used when problems are identified to ensure that customer requirements are met.

These regular audits will further ensure the stabilisation of processes and their use, as audits provide feedback on performance and identify more design gaps in the processes. Paramount to the audit process is the identification of the institution's internal and external customers, their requirements $v i s-a$-vis the organisation, and an initial benchmarking process to ascertain the competitiveness of the institution ([27]; [57]). Boase [8] suggests that, during a period of six months of using the QMS, aerospace organisations should train a team of employees to become 'internal auditors' to sustain the process into the future. This training should be done by a registered training organisation to plan, conduct, and document an internal audit by assessing and validating the status of quality improvements based on the formulised AS9100 QMS. Leonard [22] confirms this, arguing that audit training also applies inputs and corrective actions to uplift the quality of life of employees in the workplace, ensure good quality of work with service delivery of a high standard, and improve acceptable participative management between organisations and their customers.

\subsection{Phase 3: Result phase (see Figures 1 and 2)}

After the start-up and integration phases, the result phase must ensure that the AS9100 QMS is maintained and sustained by using innovative techniques to ensure continuous improvement to achieve customer and stakeholder satisfaction, which is the main focus of the AS9100 standard. This phase must ensure that a steady-state for AS9100 QMS implementation is reached.

\subsubsection{Continuous improvement}

In this phase it is a strategic imperative that aerospace organisations strive to sustain and maintain product and service integrity through the established AS9100 QMS. A trend of sustainability must be created to strengthen the link between the 13 dimensions used in all three phases (Figure 1). 'Sustainability', for the purpose of this article, can be defined as the ability to meet the needs of all customers and stakeholders through improved reliable performance, by reducing waste, without compromising the airworthiness of products and services. Aerospace organisations should seek to effect continuous improvements to make their QMS suitable through the use of the different dimensions from phase one, integrated with the support dimensions. 
Boyd and Stolzer [45] and Haupt [52] assert that, to sustain an AS9100 QMS, the key processes documented in the QMS must establish strong links between each other, thereby ensuring effective operations for product and service delivery. Their main argument is that key and support processes within the QMS should be continuously maintained to ensure sustainability. Simultaneously, resources and information must be managed in sufficient quality and quantities through monitoring, measuring, and analysing the business processes to ensure effective operations, and continually to keep ahead of development. The QMS must be a dynamic document, managed in real-time terms, to give effective and efficient visibility to all processes should potential problems materialise. This is done by continuously designing and implementing processes that speed up the delivery of products and services, eliminate wasteful periods, and quickly rectify stoppages and bottle-necks. According to Collins and Steiger [30], the continuous improvement of processes is necessary to enable prompt and quick adaptation to unforeseen challenges and threats, and to ensure adequate resilience to recover quickly - and without loss of cohesion - from mishaps and setbacks. Fakhri [27], Garengo and Biazzo [5], and Larson and Kerr [56] highlight the following five performance parameters for an AS9100 QMS to ensure continuous improvement: (1) reliability by meeting the demands placed on the aerospace industry; (2) responsiveness to demands; (3) agility to match fluctuating operational demands, which includes the provision of support to deploy assets; (4) costs of the support rendered; and (5) assets and resources control and ownership of all assets required to sustain the support system.

Haupt [52] agrees that the strategy for a sustainable, economic, and growing aerospace industry is to ensure continuous improvement, adaptive expertise through the combination of structured learning opportunities, and conductive learning that succeeds in balancing the dimension of customer and stakeholder satisfaction. The author further claims that cross-training employees is necessary to alleviate bottlenecks when key personnel are not available to sustain the QMS, while the development of technical skills provides the content that individuals will rely on to function efficiently and safely.

In order to achieve continuous improvement of the AS9100 QMS, all six support dimensions (see Figure 2) must be integrated in every approach in order to (1) continuously optimise all support functions in the QMS to achieve the maximum achievable output within the allocated resources; (2) significantly and continuously improve the knowledge and skills of employees; (3) integrate supply chain management and systems engineering in the life cycle support and management of all systems in the aerospace organisation; (4) practise accountable, compliant life cycle ownership of all allocated and acquired assets; and (5) raise a workforce that is loyal, motivated, passionate, and singularly focused on aerospace objectives ([58]; [43]; [24]). In this phase, various techniques will be applied to determine whether the way things are done at the aerospace industry correlates with exceptional results. Full transparency should also be obtained on whether the aerospace industry has made any progress.

\subsubsection{Sustained customer and stakeholder satisfaction}

The highest strategic priority within any aerospace organisation is to optimise the implementation of the AS9100 QMS to ensure customer and stakeholder satisfaction. To this end, the former seven primary dimensions, together with the six support dimensions, must act as a package deal for improving efficiency and effectiveness, using small, isolated optimisation efforts. This is valuable to the extent that a service culture of improving efficiency is created. Optimisation is a continuous effort that requires persistent managerial attention. As the AS9100 QMS improves for the organisation, and major inefficiencies are systematically removed, the focus should be shifted to bigger areas of optimisation. Managers at all levels must be assigned a clear managerial objective to continuously measure performance and output, assess internal processes for inefficiencies, and adjust their environment for continuous optimisation. The following optimisation guidelines are provided to ensure the successful sustainability of the AS9100 QMS and thus to ensure customer and stakeholder satisfaction ([7]; [1]; [10]; [2]; [57]; [59]; [44]; [46]; [17]):

- $\quad$ A high level of resilience can be obtained where management does continuous research on how to improve processes, procedures, and work activities, supported by the correct forms and checklists for record-keeping. Management should also provide education or coaching presentations of the AS9100 standard, using training days. Employees need training in the right areas, and quality goals should be the driver of training needs.

- The primary requirement for optimising core and support processes, and their execution to ensure continued quality of products and service, is the comprehensive implementation of the 
AS9100 standard and compliance verification, which establishes common technical requirements and administrative procedures for the aerospace management.

- The development of required processes, procedures, and work activities with key functional personnel is very important in order to manage the correct indicators for quality work. To achieve bottom-line quality results, the focus should be on internal and external processes to ensure quality consistency.

- Questionnaires should be used to clarify customers' and stakeholders' feedback to develop strategies for rectifying serious issues. The questionnaire would enable the aerospace organisation to gain important knowledge and understanding of the environmental requirements. Customer surveys also enable the organisation to determine future targets, trends, and comparisons based on customer requirements.

- To become a knowledgeable organisation in the application of the AS9100, regular management review meetings must be held to learn valuable lessons through a team approach. This will help to ensure compliance with the AS9100 standard. The focus should be on strategies and activities that result in improvements in all five major performance measure areas of customer satisfaction, operational measures, quality measures, financial measures, and employee satisfaction measures.

- A corrective and preventative growth action path should be established, using a constant learning and deliberate intervention system to facilitate the seamless implementation of the AS9100 QMS, where quality optimisation becomes not a separate activity, but rather a way of life for every employee, ensuring sustainability in his or her job responsibilities.

- A logical progression process with consistent and predictable results should be obtained by investing in every employee's skills development. Mentoring high-potential individuals to develop leadership skills for acting as project managers in the 20 different elements of the QMS will make the standardised efforts and configuration management of processes easy.

- To improve processes, a baseline (the 'as is' situation) must be determined at the outset to form a valid basis for measuring progress and improvement. Also, measures for determining progress must be developed, through which results must be periodically delivered in a tangible form rather than as a single outcome at the end of the AS9100 QMS project.

- Establishing records to demonstrate functionality is the key to success in achieving and sustaining the AS9100 standard in the QMS. The strength of the AS9100 standard relies on defining the correct processes, measuring the processes correctly to ensure quality, controlling the processes that specify how baselines supervise and regulate their functional work, improving the processes to stabilise improved quality work, and documenting all quality activities correctly.

- $\quad$ Throughout the project, key internal team members must be an integral part of the process to ensure long-term, sustainable improvements once the project is completed. When the QMS has been in operation for a few months and has stabilised, it is normally time to schedule the phase one registration audit. The selected registration body will first perform an audit of the documentation and then, if documents meet the requirements of the standard, the registrar will visit the facility and perform a phase one audit to ensure that all applicable AS9100 or related standard requirements have been met.

\section{CONCLUSION}

The main aim of the research reported in this article was to develop a framework for applying an AS9100 QMS to aerospace organisations, and to answer the research question: Is there a direct correlation between an AS9100 QMS framework and its successful implementation? The relevant literature on various QMS definitions and QMS related articles was studied, and these sources revealed that there is a high regard for such a QMS framework in implementing AS9100 successfully. The literature sources were divided into small relevant parts based on QMS definitions, principles, concepts, methods, and initiatives. QMS-related articles revealed valuable information on the original concepts of QMS, indicating a high regard for 13 critical dimensions, divided into seven primary and six supportive dimensions, for the successful implementation of an AS9100 QMS. The 13 dimensions are found in most quality improvement processes, as they incorporate the prescriptions for managing a QMS. A conceptual framework for AS9100 QMS (see Figure 1) was provided to clarify the new thought process.

This study contributes to the literature in three ways. First, having analysed ISO concepts, it provides evidence for the need for an AS9100 QMS framework. Second, a new AS9100 QMS framework based 
on 13 dimensions has been developed, with the relationship between the 13 dimensions indicated (see Figure 2). Third, three phases are introduced for the implementation of the framework, aiming at a higher level of ISO implementation to achieve more operational benefits by integrating the 13 dimensions. The success of any AS9100 QMS depends on a framework that holistically covers, through the systems-thinking approach, all of the relevant dimensions necessary to contribute towards product and service delivery. The proposed framework contributes to the body of knowledge of AS9100 implementation by using a simplistic three-stage implementation transformation process.

The implication of such a framework is that aerospace organisations must produce, and continually improve, safe, reliable products that meet or exceed customer and applicable statutory regulatory requirements. The intention of the framework is systematically to standardise the requirements as far as possible for all levels of the supply chain globally. This should result in an improved quality schedule and cost performance by the reduction or elimination of organisations' unique requirements, facilitating wider application of good practice.

The qualitative research conducted indicated that the framework should empirically validate the 13 dimensions to measure not only their practical acceptance, but also customer attitudes towards the framework. This will contribute hugely to a better understanding of AS9100 QMS implementation. The comprehensive development of an instrument is necessary to measure the extent of levels of implementation of the 13 dimensions in aerospace organisations.

The study contributes to the existing literature by providing a more complete and integrated view of the 13 dimensions in support of AS9100 implementation. This can be used to boost the business activities that organisations desire to perform better than their competition, creating a competitive advantage for them. From an academic perspective, the research enhances insight and offers a recommended methodology for aerospace organisations by introducing a framework (see Figure 1) with relationship interactions that contribute to a sense of organisational worth and prosperity. A natural progression of this work would be to determine the relationship interactions by developing an instrument to measure the extent of levels of implementation of the 13 dimensions in aerospace organisations.

As the current research focused only on the principles and the clauses of implementing an AS9100 QMS, it offers several opportunities for further research. Future research would be useful to determine the relationships between the 13 dimensions in the AS9100 QMS framework (Figure 1), and the role of each individual dimension in implementing the AS9100 QMS framework, and to extend the implementation of the framework to other service industries, both locally and globally. A focus on the relationships between the 13 dimensions in the AS9100 QMS framework (Figure 1) and the role of each individual dimension in implementing the AS9100 framework will be of much value. The framework can be used by organisations as a method that they can consider implementing in order to achieve business excellence. The research results show that the power of the 13 dimensions lies in their application and use. Additional future research, based on the conceptualisation of the framework (Figure 1) and its usefulness, will contribute to the development of a comprehensive understanding of how to implement the framework as a whole with all 13 dimensions, thus offering organisations the opportunity to transform in order to achieve excellence.

\section{REFERENCES}

[1] Barker, E.M. 2002. Aerospace's AS9100 QMS Standard. Quality Digest.Web [Online]. Available: http://www.qualitydigest.com/magazine/2002/may/article/aerospaces-as9100-qms-standard.html (accessed: 3 November 2014).

[2] Foster, S.T. 2015. Quality management and techniques ( $5^{\text {th }}$ ed.). South-Western Cengage Learning.

[3] Steudel, T.H.J. 2003. What every employee needs to know about AS9100: A pocket guide to the basics,. [Online]. Steudel \& Schultz. Available: http://www.scribd.com/document/346081073/AS-9100-POCKETGUIDE-pdf.

[4] TUVRheinland.Web. 2016. AS9100C: How to effectively interpret the evolving quality management requirements in the aerospace industry [Online]. http://www.tuv.com/media/usa/whitepaper/as9100c.pdf (accessed: 18 November 2014).

[5] Garengo, P. \& Biazzo, S. 2012. From ISO quality standards to an integrated management system: An implementation process in SME. Total Quality Management \& Business Excellence, 1(26) [Online]. Available: http: //doi.org/10.1080/14783363.2012.704282 (accessed: July 2015).

[6] Oakland, J.S. 2011. Total Quality Management: Text with cases. Oxford: Martins ButterworthHeinemann. 
[7] Al-Rawahi, A.M.S. \& Bashir, H.A. 2011. On the implementation of ISO 9001:2000: A comparative investigation. The TQM Journal, 23(6), 673-687 [Online]. Available: http://doi.org/10.1108/17542731111175275.

[8] Boase, B. 2011. A practical guide for the implementation of a quality management system for National Meteorological and World Meteorological Organisation [Online]. Available: http://www.wmo.int/pages/prog/hwrp/qmf-h/documents/ext/QM_Guide_NMHSs_V10.pdf.

[9] Laux, C.M. \& Hurburgh, C.R. 2007. The impacts of a formal quality management system: A case study of implementing ISO 9000 at Farmers Cooperative Co., lowa. 3274884, 174 [Online]. Available: https: //vpn.utm. my/docview/304855268?accountid=41678.

[10] Evans J.R. 2017. Quality management organisation and strategy (6 $6^{\text {th }}$ ed.). South-Western Cengage Learning.

[11] Sivakumar, V.M. 2013. Theory and practice of knowledge managed ISO 9001 : 2000 supported quality system. [Online]. Available: http://doi.org/10.1108/TQM-10-2011-0063.

[12] Goetsch, D.L. \& Davis, S.B. 2012. Total quality management: An internal customer approaches $\left(7^{\text {th }}\right.$ ed.). New Jersey: Pearson Custom Publishing..

[13] Campbell, K. 2010. South African aerospace industry should be seen as a 'national university'. Engineering News. CSIR's Third Biennial Conference in Pretoria.

[14] Karapetrovic, S., Fa, M.C. \& Saizarbitoria, I.H. 2010. What happened to the ISO 9000 lustre? An eightyear study. Total Quality Management \& Business Excellence, 21(3), 245-267 [Online]. Available: http: / /doi.org/10.1080/14783360903553149.

[15] Thomas, K.T. 2006. Quality management system for defence aeronautical industry. Defence Science Journal, 56(1), 21-30.

[16] Fatima, M. 2014. Impact of ISO 9000 on business performance in Pakistan: Implications for quality in developing countries. The Quality Management Journal, 21(1), 16-24 [Online]. Available: http: / / search.proquest.com/docview/1503666079?accountid=25704

[17] Tomic, B. 2011. Quality management system for the aerospace industry. International Symposium, Engineering Management and Competitiveness 2011, 137-142 [Online]. http://www.tfzr.uns.ac.rs/emc2012/emc2011/Files/B 02.pdf

[18] Lee, W.K. \& Kim, S.J. 2015. Roles of safety management system (SMS) in aircraft development. International Journal of Aeronautical and Space Sciences, 16(3), 451-462 [Online]. Available: http://doi.org/10.5139/IJASS.2015.16.3.451

[19] Myhrberg, E.V. \& Crabtree, D.H. 2006. A practical field guide for AS 9100. ASQ Quality Press: Gulf Coast. ISBN 10: 0873896825

[20] Coppinger, C. 2003. The new AS9100 lifts off. Engineering News. Quality Online. https://www.amazon.com./Practical-Field-Guide-AS9100/dp/0873896823.

[21] Pycraft, M., Singh, H. \& Phihlelea, K. 2008. Operations Management (Southern Africa ed.). Pearson Education: South Africa.

[22] Leonard, C. 2011. Quality assurance in the aerospace industry: Implementation of AS 9100 quality management standard at an SME. Faculty of Engineering: University of Stellenbosch

[23] Sharma, A., Garg, D. \& Agarwal, A. 2012. Quality management in supply chains: The literature review. International Journal for Quality Research, 6(3), 193-206.

[24] Stadnicka, D. \& Antosz, K. 2015. Continuous improvement practice in large enterprises: Study results. International Journal for Quality Research, 9(1), 9-26.

[25] Miguel, P.A.C. \& Dias, J.C.S. 2009. A proposed framework for combining ISO 9001 quality system and quality function deployment. The TQM Journal, 21(6), 589-60.

[26] Oschman, J.J. 2017. The role of strategic planning in implementing a total quality management framework: An empirical view. The Quality Management Journal, 24(2), 41-56.

[27] Fakhri, M. 2010. Quality management systems design and implementation. Sudan: LAP LAMBERT: Academic Publishing.

[28] Gordon, D.K. 2003. Aerospace Quality Management System -AS 9100, 1-24. Presentation transcript: Americans Aerospace Quality Group.

[29] Russell, J.P. 2005. The ASQ audit handbook: Principles, implementation, and use (3rd ed.). Milwaukee: ASQ Quality Press. Available: https://asq.org/quality-press/display-item?item=H1435.

[30] Collins, J.W. \& Steiger, D.S. 2009. The memory jogger 9001:2008: Implementing a process approach compliant to ISO 9001:2008 Quality Management System Standard. Goal Q P C Inc: United Kingdom.

[31] Munroe, T. 2007. How to formulate your quality policy statement and quality objectives in your ISO quality manual [Online]. Available: http://ezinearticles.com/?How-to-Formulate-your-Quality-PolicyStatement-and-Quality-Objectives-in-your-ISO-Quality-Manual\&id=532447.

[32] Anderson, L.S. \& Anderson, D. 2010. The change leader's roadmap: How to navigate your organization's transformation (2nd ed.). San Francisco: Wiley: Pfeiffer. Available: https://www.amazon.com/changeleaders-roadmap-organisations-transformation/dp/0470648066. ISBN: 978-0-470-64806-3.

[33] Harun, K. \& Cheng, K. 2010. An integrated modelling method for assessment of manufacturing quality systems applied to aerospace manufacturing supply chains. Proceedings of the 6th CIRP-Sponsored International Conference on Digital Enterprise Technology, pp 1687-1708. Available: https: / /link.springer.com/chapter/10.1007/978-3-642-10430-5_126.

[34] Chen, H.R. \& Cheng, B.W. 2012. Applying the ISO 9001 process approach and service blueprint to hospital management systems. The TQM Journal, 24(5), 418-432 [Online]. Available: http://doi.org/10.1108/17542731211261575. 
[35] Kreamer-Mbula, E. 2008. Sectoral analysis of the aerospace industry in South Africa: Sector studies research project. Pretoria: Human Sciences Research Council.

[36] Yahya, S. \& Goh, W. 2001. The implementation of an ISO 9000 quality system. The International Journal of Quality and Reliability Management. Vol. 18 No. 9, pp. 941-966.

[37] Rosenberg, B. 2006. Nadcap: The path to excellence and quality for aerospace special processes. SAE International's Aerospace.

[38] Abdallah, A.B. 2013. The influence of "soft" and "hard" total quality management (TQM) practices on total productive maintenance (TPM) in Jordanian manufacturing companies. International Journal of Business and Management, 8(21), 1-13 [Online]. Available: http://doi.org/10.5539/ijbm.v8n21p1.

[39] Dervitsiotis, K.N. 2010. A framework for the assessment of an organisation's innovation excellence. Total Quality Management \& Business Excellence, 21(9), 903-918 [Online]. Available: http://doi.org/10.1080/14783363.2010.487702.

[40] Fotopoulos, C.B. \& Psomas, E.L. 2009. The impact of "soft" and "hard" TQM elements on quality management results. International Journal of Quality \& Reliability Management, 26(2), 150-163 [Online]. Available: http://doi.org/10.1108/02656710910928798.

[41] Gates, L.P. 2010. Strategic planning with critical success factors and future scenarios: An integrated strategic planning framework. Software Engineering Institute, Hanscom AFB: Carnegie Mellon University, 67. Available: http://repository.cmu.edu/sei.

[42] Imbeah, K.A. 2012. Framework for the implementation of total quality management (TQM) in real estate firms in Ghana. Kwame Nkrumah University of Science and Technology.

[43] Lewis, W.G., Pun, K.F. \& Lalla, T.R.M. 2007. The effect of ISO 9001 on TQM implementation in SME in Trinidad. West Indian Journal of Engineering, 30(1), 1-16 [Online]. Available: https://64.28.139.231/eng/wije/vol3001_jul2007/documents/ISO9001onTQMmplementation.pdf.

[44] Soko, M. 2006. The aerospace industry: Prospects for strategic co-operation among the IBSA countries. The South African Institute of International Affairs - Johannesburg: University of Witwatersrand.

[45] Boyd, D. \& Stolzer, A. 2015. Causes and trends in maintenance-related accidents in FAA-certified single engine piston aircraft. Journal of Aviation Technology and Engineering, 5(1), 17. [Online]. Available: http: / /doi.org/10.7771/2159-6670.1123.

[46] Stolzer, A. \& Halford, C. 2004. Quality in airline safety: Quality methods and tools are needed to manage new directions, Journal of Aviation/Aerospace Education \& Research, 13(3), 27-32 [Online]. Available: https: / /commons.erau.edu/cgi/viewcontent.cgi?article=1546\&context-jaaer.

[47] Schlickman, J.J. 2003. ISO 9001:2000 quality management system design. Boston: Artech House.

[48] Smithers Quality Assessments. 2010. AS 9100 certification and registration process [Online]. Available: http://www.smithersregistrar.com/as9100/page-process-to-as9100.shtml.

[49] To, W.M., Lee, P.K.C. \& Yu, B.T.W. 2011. ISO 9001:2000 implementation in the public sector: A survey in Macao SAR, the People's Republic of China. The TQM Journal, 23(1), 59-72 [Online]. Available: http: / /doi.org/10.1108/17542731111097498.

[50] Fotopoulos, C.V., Psomas, E.L. \& Vouzas, F.K. 2010. Investigating total quality management practice's inter-relationships in ISO 9001:2000 certified organisations. Total Quality Management \& Business Excellence, 21(5), 503-515 [Online]. Available: http://doi.org/10.1080/14783363.2010.481512.

[51] Abdullah, M.M.B., Uli, J. \& Tarí, J.J. 2008. The influence of soft factors on quality improvement and performance: Perceptions from managers. The TQM Journal, 20(5), 436-452 [Online]. Available: http://doi.org/10.1108/17542730810898412.

[52] Haupt, P. 2005. ASSEGAI: A strategy for a sustainable, economical and growing aerospace industry. Department: Science and Technology RSA.

[53] Conti, T. 2010. Systems thinking in quality management. The TQM Journal, 22(4), 352-368 [Online]. Available: http://doi.org/10.1108/17542731011053280.

[54] Bureau Veritas Audit Team. 2010. Management system certification audit report for the 2nd surveillance of Daliff Precision Engineering (Pty) Ltd.

[55] ASE International Group. 2010. AS 9101 revision D: Quality management systems audit requirements for aviation, space, and defence organizations.

[56] Larson, P.D. \& Kerr, S.G. 2007. Integration of process management tools to support TQM implementation: ISO 9000 and activity-based costing. Total Quality Management \& Business Excellence, 18(1-2), 201-207 [Online]. Available: http://doi.org/10.1080/14783360601053434.

[57] Farooqui, R.U. \& Ahmed, S.M. 2009. ISO 9000: A stepping stone to total quality management for construction companies? Latin American and Caribbean Conference for Engineering and Technology, June, 2009.

[58] Kuo, T., Chang, T.J., Hung, K. \& Lin, M. 2009. Employees' perspective on the effectiveness of ISO 9000 certification: A total quality management framework. Total Quality Management \& Business Excellence, 20(12), 1321-1335 [Online]. Available: http://doi.org/10.1080/14783360903250530.

[59] Johansson, D. \& Stenmark, H. 2005, Sub-tier process approval in the aerospace industry: A case study at Volvo Aero Corporation. Proceedings of Winter Simulation Conference. Gothenburg, Sweden.

[60] International Organization for Standardization (ISO). 2015. ISO 9001 revision [Online]. Available: http://www.iso.org/iso/home/standards/management-standards/iso_9000/iso9001_revision.htm. 